\title{
Numerical Analysis of Friction Conditions on Temperature and Phases Within Forged Ti-6Al-4V Aeroengine Drum
}

Shiyuan Luo ( $\nabla$ shiyuanluo@wust.edu.cn )

Wuhan university of Science and Technology

\section{Yongxin Jiang}

Key Laboratory of Metallurgical Equipment and Control Technology, Ministry of Education, School of Machinery and Automation, Wuhan University of Science and Technology, Wuhan 430081, China

\section{Po Zhang}

Key Laboratory of Metallurgical Equipment and Control Technology, Ministry of Education, School of Machinery and Automation, Wuhan University of Science and Technology, Wuhan 430081, China

\section{Fengping Yu}

Technology Center, Wuxi Turbine Blade Co., Ltd., Wuxi 214174, China

\section{Siwen Liu}

China Railway Siyuan Survey and Design Group Co., Ltd., Wuhan 430063, China

\section{Research Article}

Keywords: Friction condition, titanium alloy, drum forging, phase transition, FE modeling

Posted Date: April 27th, 2021

DOl: https://doi.org/10.21203/rs.3.rs-446468/v1

License: (c) (i) This work is licensed under a Creative Commons Attribution 4.0 International License. Read Full License 


\title{
Numerical analysis of friction conditions on temperature and phases within
}

\section{forged Ti-6Al-4V aeroengine drum}

\author{
Shiyuan Luo ${ }^{\mathrm{a}, \mathrm{b}, *}$, Yongxin Jiang, ${ }^{\mathrm{a}, \mathrm{b}}$, Po Zhang ${ }^{\mathrm{a}, \mathrm{b}}$, Fengping Yu ${ }^{\mathrm{c}}$, Siwen Liu ${ }^{\mathrm{d}}$ \\ ${ }^{a}$ Key Laboratory of Metallurgical Equipment and Control Technology, Ministry of Education, School of \\ Machinery and Automation, Wuhan University of Science and Technology, Wuhan 430081, China \\ ${ }^{\mathrm{b}}$ Hubei Key Laboratory of Mechanical Transmission and Manufacturing Engineering, School of \\ Machinery and Automation, Wuhan University of Science and Technology, Wuhan 430081, China \\ ${ }^{\mathrm{c}}$ Technology Center, Wuxi Turbine Blade Co., Ltd., Wuxi 214174, China \\ ${ }^{d}$ China Railway Siyuan Survey and Design Group Co., Ltd., Wuhan 430063, China
}

\begin{abstract}
Friction conditions significantly impact the temperature and phases of titanium forged parts, further directly affecting the microstructures and mechanical properties of final parts. In this paper, a $2 \mathrm{D}$ simplified FE model combined with phase transition equations is developed to simulate Ti-6Al-4V drum forging procedure. Then, friction effects on the temperature and phases of the forged drum are numerically analyzed and verified by experiments. Results indicate that unlike little influence on $\alpha+\beta$ phase, improving friction obviously decreases the general levels of temperature and $\beta$ phase and increases the homogeneities of $\alpha$ and $\beta$ phases within the forged drum, which are associated with cooling rates and the heating effects of friction and deformation.
\end{abstract}

Keywords: Friction condition; titanium alloy; drum forging; phase transition; FE modeling

\footnotetext{
* Corresponding author. Tel.: +86 27 68862283. E-mail address: shiyuanluo@wust.edu.cn (S. Luo)
} 


\section{Introduction}

Titanium drums are crucial aeroengine components, which have a significant influence on the reliability of aircrafts [1]. According to previous works, the forging of titanium aeronautic components is a difficult operation [2-4], and friction conditions greatly affect the temperature and phases of forged parts $[5,6]$, further impacting the corrosion resistance and fatigue life of final parts $[7,8]$. Hence, an investigation of friction effects on temperature and phases within titanium forged drums is of vital importance and urgent necessity to optimize their ultimate mechanical properties and service life.

Ti-6Al-4V, including $\alpha$ and $\beta$ phases, is a representative dual phase titanium alloy [9]. Focusing on its phase transition behaviors, two predictive equations have been carried out. Hereinto, a simplified Avrami equation developed by Sha et al. [10] was used to identify the $\alpha \rightarrow \beta$ phase transition characteristics in a heating operation. In contrast, a Johnson-Mehl-Avrami (JMA) equation established by Malinov et al. [11] was utilized to predict $\beta \rightarrow \alpha+\beta$ phase transition behaviors in a cooling operation. Moreover, embedding the above equations into 2D FE approaches, Quan et al. [12] studied the phase transition characteristics of a Ti-6Al-4V cylinder during the non-isothermal upsetting procedure. Bruschi et al. [13] revealed the phase transition behaviors of a Ti-6Al-4V blade section in the hot forging operation. Luo et al. [14] reported the phase transition characteristics of a Ti-6Al-4V drum during hot forging and subsequent cooling operations. Furthermore, based on 3D FE approaches, Ducato et al. [15] reflected the phase transition behaviors in a Ti-6Al-4V flange hot forging procedure. Buffa et al. [16] studied Ti-6Al-4V phase distributions during a welding process and verified the simulated results by experiments. Luo et al. [17] revealed the phase transition behaviors of a large Ti-6Al-4V turbine blade during the hot forging operation. Note that although plenty of studies have been performed, however, none of them is tied to friction effects on the temperature and phase of Ti-6Al-4V drums, particularly on 
their general levels and distribution uniformities.

Consequently, the intention of this paper is to investigate the influences of friction conditions on the temperature and phases within Ti-6Al-4V aeroengine drum in the forging procedure. For this aim, a 2D simplified FE model combined with phase transition equations is established by DEFORM software. Then, based on two evaluation indexes, friction effects on the temperature and phase transition characteristics of the forged drum are analyzed quantitatively. Finally, experiments are conducted to demonstrate the validation of simulated results.

\section{FE modeling}

Owing to the axisymmetric structure of drums described in Fig. 1(a), a 2D simplified FE model is developed to simulate their forging procedure $[12,14]$, as shown in Fig. 1(b). The mesh details of forging dies and workpiece are depicted in Fig. 1(c).

(a)

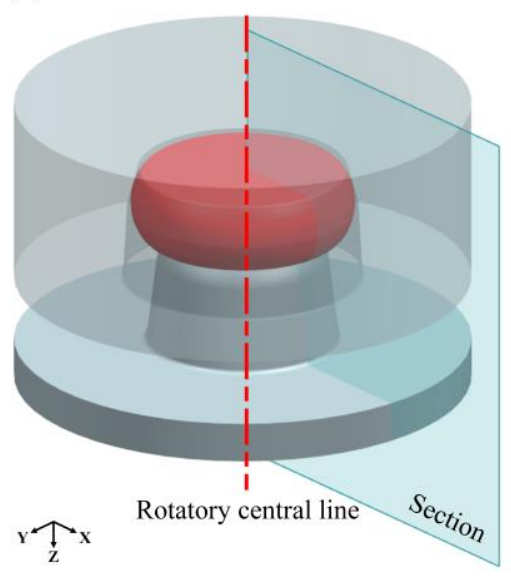

(b)

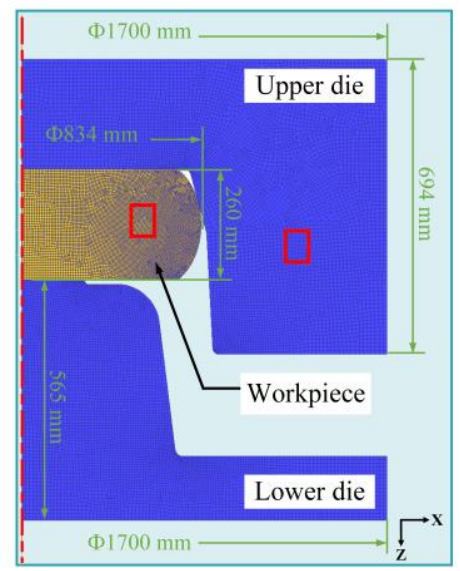

(c)

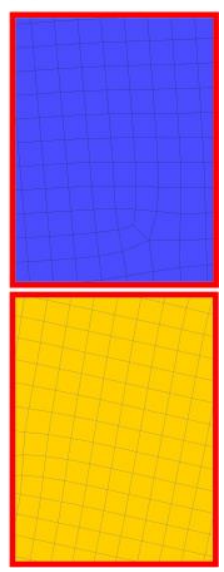

Fig. 1. Drum structure (a), 2D simplified FE model (b) and the mesh details of dies and workpiece (c).

Moreover, the material of workpiece is Ti-6Al-4V alloy with stress-strain curves referring to [18].

Its heat capacity $(C)$, Young modulus $(E)$ and thermal conductivity $(K)$ are described by Eqs. (1)-(3) [19].

The material of dies is AISI H13 steel with material parameters referring to [20].

$C=2.36+3 \times 10^{-4} \times T+2 \times 10^{-6} \times T^{2}$ 


$$
E=104.94-0.052079 \times T
$$

$$
K=0.0131 \times T+6.45
$$

Then, the simplified Avrami and JMA equations are respectively used to predict the phase transition percentages of $\alpha \rightarrow \beta$ and $\beta \rightarrow \alpha+\beta$, corresponding to the heating and cooling processes. The above two equations are given below [13]:

$$
\begin{aligned}
& f_{v_{(\alpha \rightarrow \beta)}}=1-\exp \left\{A\left[\left(T-T_{s}\right) /\left(T_{e}-T_{s}\right)\right]^{D}\right\} \\
& f_{v_{(\beta \rightarrow \alpha+\beta)}}=1-\exp \left(-b t^{n}\right)
\end{aligned}
$$

where $f_{v(\alpha \rightarrow \beta)}$ and $f_{v(\beta \rightarrow \alpha+\beta)}$ respectively denote the transformed percentage of $\beta$ and $\alpha+\beta$ phases, $T$ means the instantaneous temperature, $T_{e}=980{ }^{\circ} \mathrm{C}$ and $T_{s}=600{ }^{\circ} \mathrm{C}$ are the ending and starting temperatures of phase transformation, $A=-1.86$ and $D=4.35$ are material constants [17], $t$ is the cooling time, $n=1.35$ is the Avrami index [14], and b is the coefficient decided by the time-temperature-transformation (TTT) start curve [13].

Furthermore, to simulate friction behaviors in the drum forging procedure simply and effectively, a shear friction model ignoring the effect of sliding velocity on die-workpiece interfaces is employed [21].

$$
\tau=m k
$$

where $\tau$ is frictional stress, $m$ represents the friction factor and $k$ denotes the shear stress.

Finally, the critical parameters of materials and hot forging procedure are listed in Table 1. Besides, to detailedly describe the distributions of temperature and phases within the forged drum, the 2D simulated results are transformed into 3D ones by using the postprocessor of DEFORM software [14].

Table 1 The critical parameters of materials and hot forging procedure.

\begin{tabular}{lcc}
\hline Parameters & Workpiece & Dies \\
\hline Material & Ti-6Al-4V & AISI H13
\end{tabular}


Density $\left(\mathrm{Kg} / \mathrm{mm}^{3}\right)$

Poisson's ratio

Heat capacity $\left(\mathrm{N} /\left(\mathrm{s}^{\circ} \mathrm{C}\right)\right)$

Young's modulus (MPa)

Thermal conductivity $\left(\mathrm{N} /\left(\mathrm{s} \mathrm{mm}^{2}{ }^{\circ} \mathrm{C}\right)\right)$

Emissivity

Convection coefficient $\left(\mathrm{N} /\left(\mathrm{s} \mathrm{mm}^{\circ} \mathrm{C}\right)\right)$

Heat transfer coefficient $\left(\mathrm{N} /\left(\mathrm{s} \mathrm{mm}^{\circ} \mathrm{C}\right)\right)$

Initial workpiece temperature $\left({ }^{\circ} \mathrm{C}\right)$

Initial die temperature $\left({ }^{\circ} \mathrm{C}\right)$

Forging stroke (mm)

Forging velocity $(\mathrm{mm} / \mathrm{s})$

Friction factor
$4.43 \times 10^{-6}[22] \quad 7.8 \times 10^{-6}[23]$

$0.34[24]$

$0.28[25]$

Eq. (1)

Eq. (2)

Eq. (3)

0.7 [26]

0.7 [27]

0.02 [28]

0.02 [29]

5 [30]

930

250

210

300

$0.1 / 0.2 / 0.3 / 0.4 / 0.5 / 0.6$

\section{Results and discussions}

\subsection{Evaluation indexes}

For temperature, its average $\left(T_{a v g}\right)$ and standard deviation $\left(T_{s d}\right)$ values are selected to quantitatively reflect the variations of its general level and distribution uniformity, which are defined as [17]:

$$
\begin{aligned}
& T_{a v g}=\sum_{i}^{N} T_{i} / N \\
& T_{s d}=\sqrt{\sum_{i}^{N}\left(T_{i}-T_{\text {avg }}\right)^{2} /(N-1)}
\end{aligned}
$$

where $N$ represents the total quantity of elements, and $T_{i}$ means the temperature of element $i$.

Moreover, for $\alpha$ phase, its average volume fraction $\left(f_{\text {avg }}(\alpha)\right)$ and standard deviation $\left(f_{s d}(\alpha)\right)$ values are obtained by $[6]$ :

$$
f_{\text {avg }}(\alpha)=\sum_{i}^{N} f_{i}(\alpha) / N
$$




$$
f_{s d}(\alpha)=\sqrt{\sum_{i}^{N}\left(f_{i}(\alpha)-f_{\text {avg }}(\alpha)\right)^{2} /(N-1)}
$$

where $f_{i}(\alpha)$ represents the $\alpha$ phase volume fraction of element $i$. Additionally, similar equations are employed for $\beta$ and $\alpha+\beta$ phases.

\subsection{Friction effects on temperature within forged drum}

Fig. 2(a) presents the variation range of temperature and friction effects on the maximal and minimal values $\left(T_{\max }\right.$ and $\left.T_{\min }\right)$ of the forged drum. Hereinto, the $T_{\max }$ increases from $997{ }^{\circ} \mathrm{C}$ to $1160{ }^{\circ} \mathrm{C}$, and the $T_{m i n}$ decreases from $754{ }^{\circ} \mathrm{C}$ to $692{ }^{\circ} \mathrm{C}$ with the increment of $m$ from 0.1 to 0.6 . These can be owing to the heating effects of friction and deformation. Specifically, as enhancing friction, the friction heating effect is strengthened, further leading to an obvious increment of heat generation within the internal wall area of the forged drum. In contrast, the intensive friction weakens the deformation heating effect within hard deformation areas, thereby resulting in a decrement of heat generation within the bottom area of the forged drum illustrated in Fig. 3. This view can be indirectly sustained by our previous work [5]. Moreover, as shown in Fig. 2(b), unlike the slight increment of $T_{\text {avg }}$, the value of $T_{s d}$ first dramatically drops, and then gradually increases from the level of $24^{\circ} \mathrm{C}$ as the $m$ exceeds 0.3 . This finding indicates that a reasonable range of friction conditions exists, which leads to a homogeneous distribution of temperature within the forged drum, as described in Fig. 3.

(a)

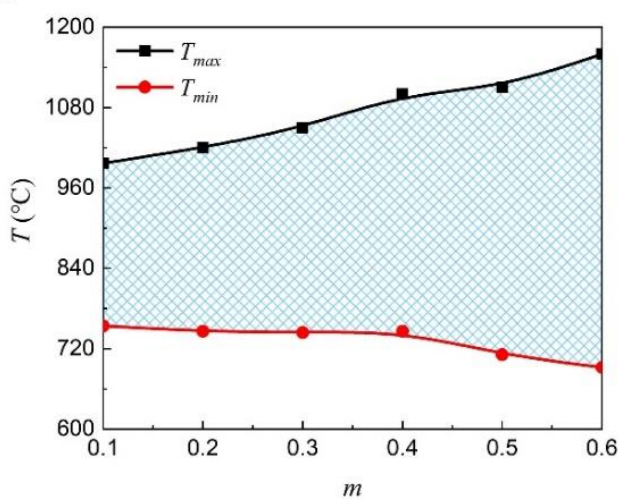

(b)

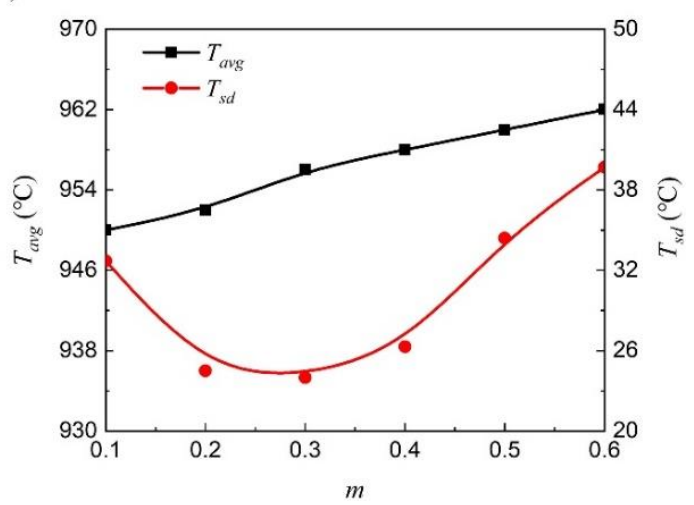

Fig. 2. Evolutions of $T_{\max }, T_{\min }, T_{\text {avg }}$ and $T_{s d}$ with the increment of $m$. 

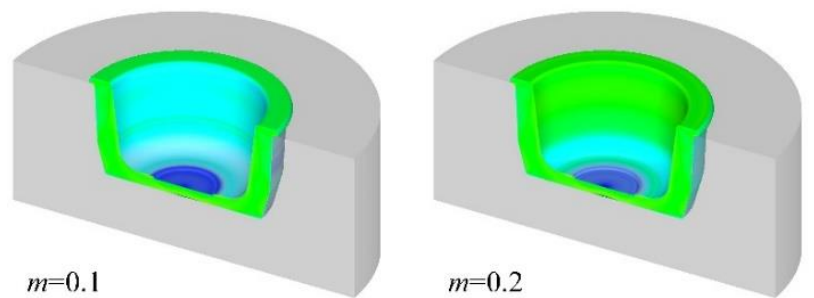

$m=0.2$
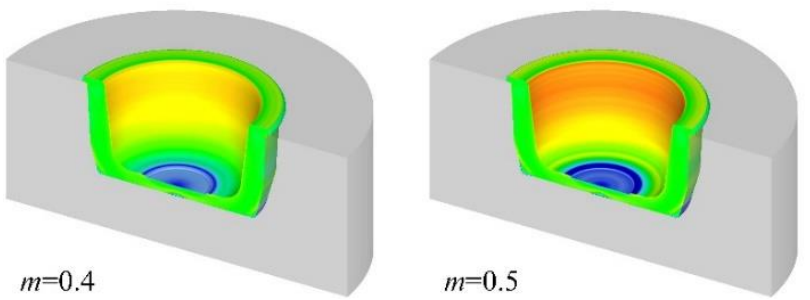
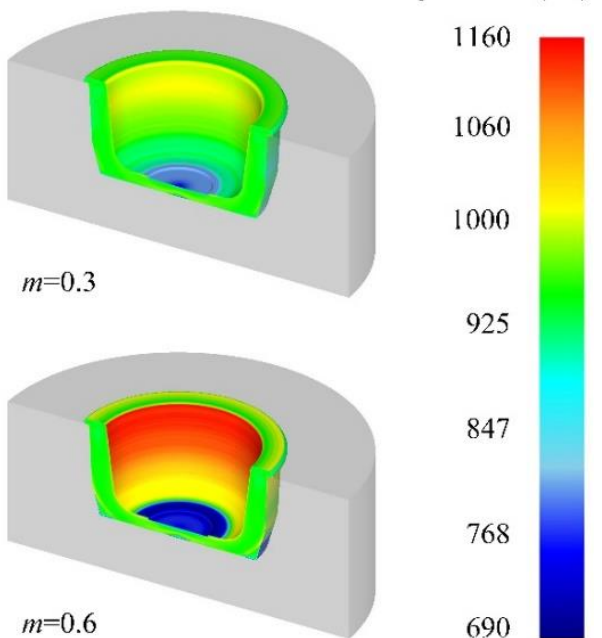

Fig. 3. Distributions of temperature under various friction conditions.

\subsection{Friction effects on phases within forged drum}

\subsection{1 $\alpha$ phase evolution and distribution}

Fig. 4(a) presents the variation range of equiaxed $\alpha$ phase volume fraction and friction effects on its maximal and minimal values $\left(f_{\max }(\alpha)\right.$ and $\left.f_{\min }(\alpha)\right)$ within the forged drum. It can be found that the $f_{\max }(\alpha)$ remains unchanged (about 36.5\%) with the increment of $m$. This is because the phase transition behavior from $\beta$ to equiaxed $\alpha$ phases only occurs when cooling rates are less than $0.03{ }^{\circ} \mathrm{C} / \mathrm{s}$. This view can be sustained by previous studies $[31,32]$, which detailedly analyzed the behaviors of Ti-6Al-4V phase transition. Moreover, the $f_{\min }(\alpha)$ decreases from $12 \%$ to $0.6 \%$ with the increment of $m$ from 0.1 to 0.6. This phenomenon is ascribed to the $\alpha \rightarrow \beta$ phase transition prompted by the strengthening of $T_{\max }$, as plotted in Fig. 2(a). Then, as shown in Fig. 4(b), the $f_{\text {avg }}(\alpha)$ decreases from $24.5 \%$ to $21.5 \%$ with the increment of $m$ from 0.1 to 0.6 . This result is highly consistent with the evolutions of $f_{\max }(\alpha)$ and $f_{\min }(\alpha)$, which can be related to the increment of $T_{\text {avg }}$ presented in Fig. 2(b). Conversely, $f_{s d}(\alpha)$ generally increases from $4.94 \%$ to $6.56 \%$ as enhancing the $m$ from 0.1 to 0.6 . This result reveals that the $\alpha$ phase distribution is more homogenous as improving friction conditions, as described in Fig. 5. 
(a)

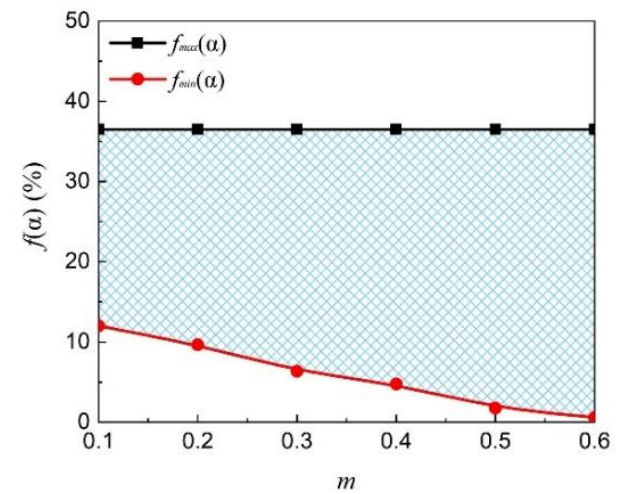

(b)

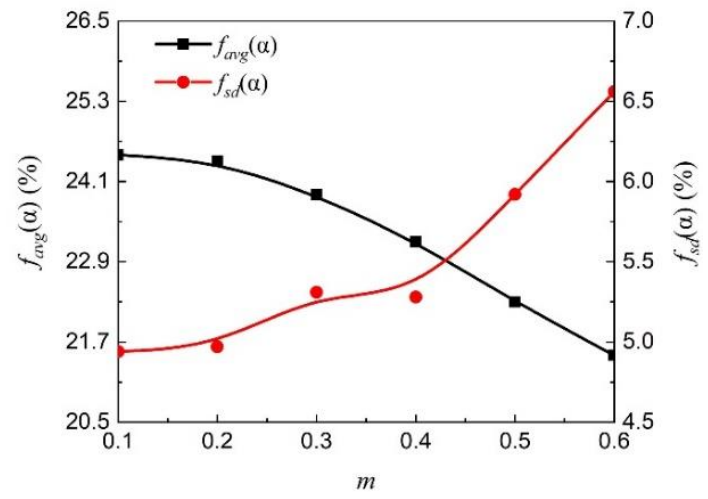

Fig. 4. Evolutions of $f_{\max }(\alpha), f_{\min }(\alpha), f_{\text {avg }}(\alpha)$ and $f_{\text {sd }}(\alpha)$ with the increment of $m$.
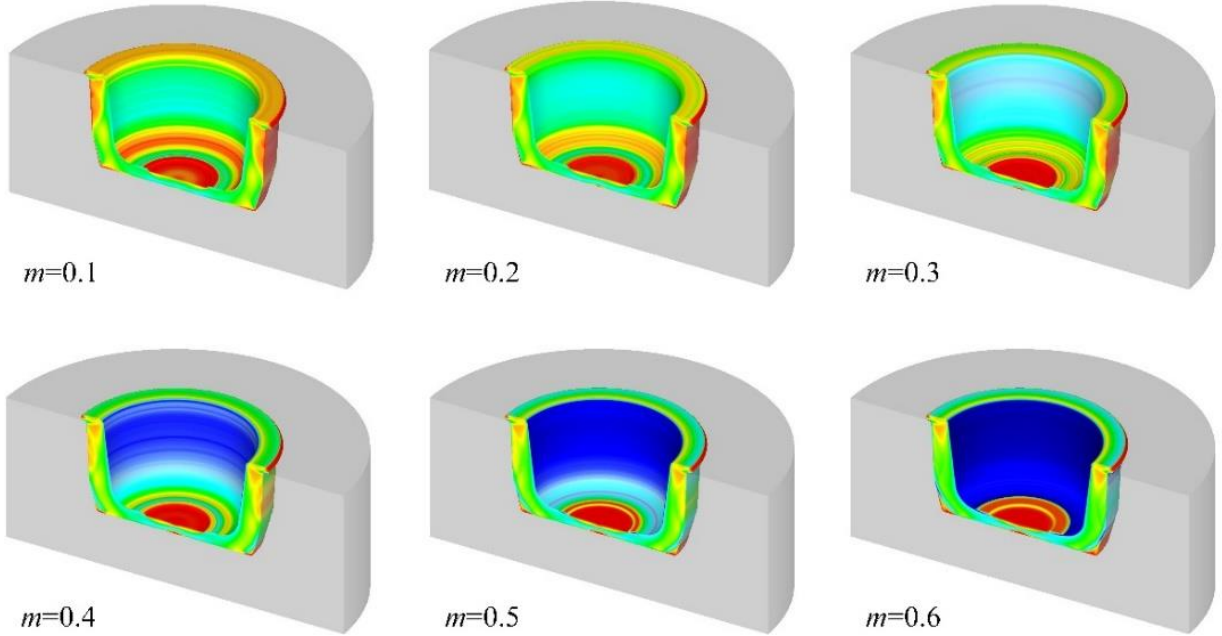

$\alpha$ phase $(\%)$

36.5

30.4

24.3

12.2

6.1

0.0

Fig. 5. Distributions of $\alpha$ phase under various friction conditions.

\subsection{2 $\beta$ phase evolution and distribution}

Fig. 6(a) presents the variation range of equiaxed $\beta$ phase volume fraction and friction effects on its maximal and minimal values $\left(f_{\max }(\beta)\right.$ and $\left.f_{\min }(\beta)\right)$ within the forged drum. Unlike $f_{\min }(\alpha)$, the $f_{\max }(\beta)$ shows an opposite evolution, which increases from $88 \%$ to $99.5 \%$ as enhancing $m$ from 0.1 to 0.6 . The above phenomenon is also owing to the $\alpha \rightarrow \beta$ phase transition influenced by the heating effects of friction and deformation, as mentioned in Section 3.3.1. Moreover, it can be found that the $f_{\min }(\beta)$ keeps unchanged (about $63.5 \%$ ) and presents good consistency with the evolution of $f_{\max }(\alpha)$ described in Fig. 4(a). Then, as shown in Fig. 6(b), the $f_{a v g}(\beta)$ rises from $75.3 \%$ to $78.5 \%$ with the increment of $m$, which is related to the strengthening of $T_{a v g}$ illustrated in Fig. 2(b). Besides, the $f_{s d}(\beta)$ increases from $4.94 \%$ to $6.56 \%$ as 
increasing the $m$ from 0.1 to 0.6 , showing the same evolution with $f_{s d}(\alpha)$. This result indicates the $\beta$ phase distribution is more homogenous with a good lubricated condition, as described in Fig. 7.

(a)

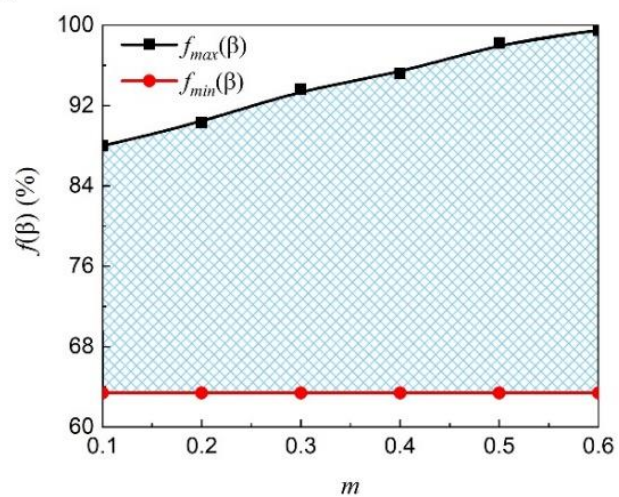

(b)

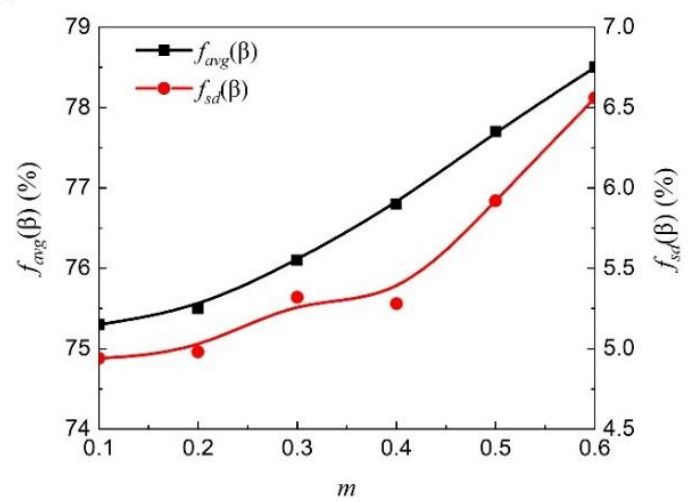

Fig. 6. Evolutions of $f_{\max }(\beta), f_{\min }(\beta), f_{\text {avg }}(\beta)$ and $f_{\text {sd }}(\beta)$ with the increment of $m$.
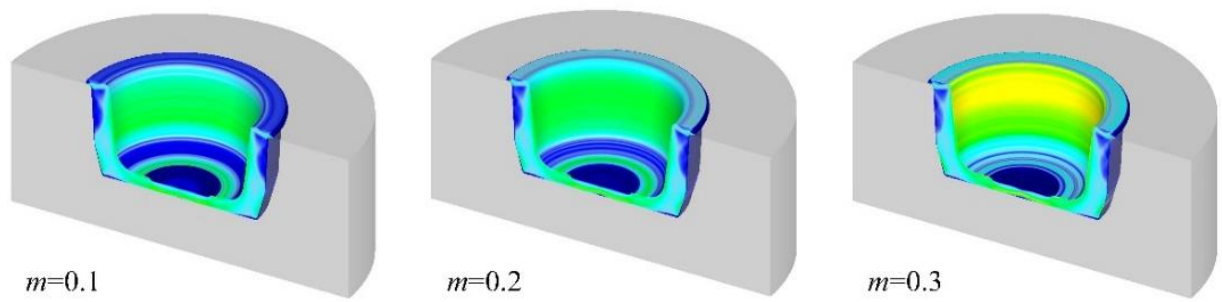

$\beta$ phase (\%)

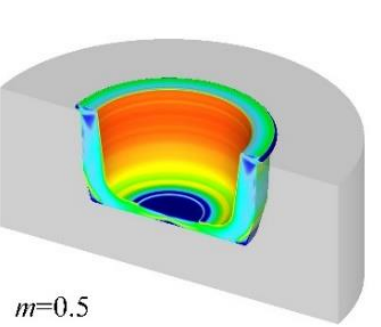

$m=0.3$

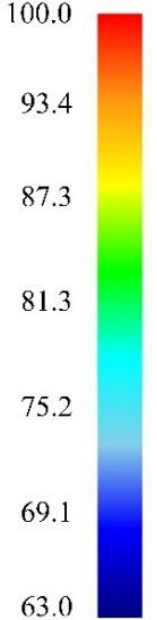

Fig. 7. Distributions of $\beta$ phase under various friction conditions.

\subsection{3 $\alpha+\beta$ phase evolution and distribution}

Fig. 8(a) presents the variation range of lamellar $\alpha+\beta$ phase volume fraction and friction effects on its maximal and minimal values $\left(f_{\max }(\alpha+\beta)\right.$ and $\left.f_{\min }(\alpha+\beta)\right)$ within the forged drum. Distinct from $\alpha$ and $\beta$ phases, the volume fraction of $\alpha+\beta$ phase is dozens of times smaller, and both values of $f_{\max }(\alpha+\beta)$ and $f_{\min }(\alpha+\beta)$ (about $0.6 \%$ and $0 \%$ ) remain basically unchanged with the increment of $m$. This finding suggests that friction has little effect on the $\beta \rightarrow \alpha+\beta$ phase transition within the forged drum. These phenomena are ascribed to the reason that the large forging velocity $(300 \mathrm{~mm} / \mathrm{s})$ shortens the forging 
time $(0.7 \mathrm{~s})$, further limiting the phase transition time, thereby causing a tiny volume fraction of $\alpha+\beta$ phase. This view can be proved by the investigation of Pan et al. [33], which detailedly described the time-temperature-transformation curves of titanium alloy. Moreover, as shown in Fig. 8(b), both values of $f_{\text {avg }}(\alpha+\beta)$ and $f_{s d}(\alpha+\beta)$ can be also considered to maintain invariable with the increment of $m$, corresponding to about $0.01 \%$ and $0.004 \%$ respectively. This result suggests that the distribution of $\alpha+\beta$ phase is more homogenous than the ones of $\alpha$ and $\beta$ phases, as presented in Fig. 9.

(a)

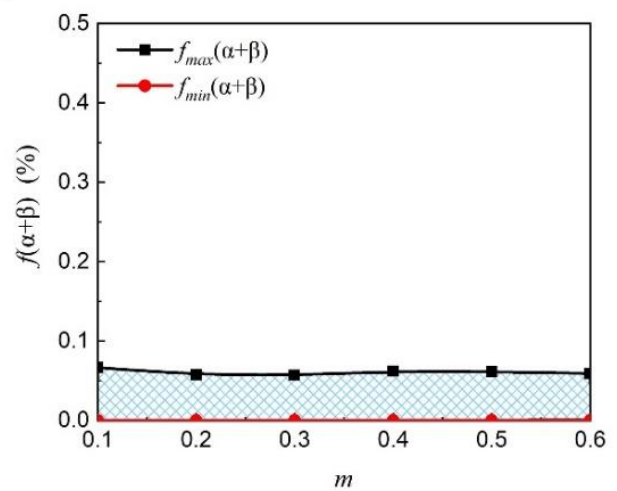

(b)

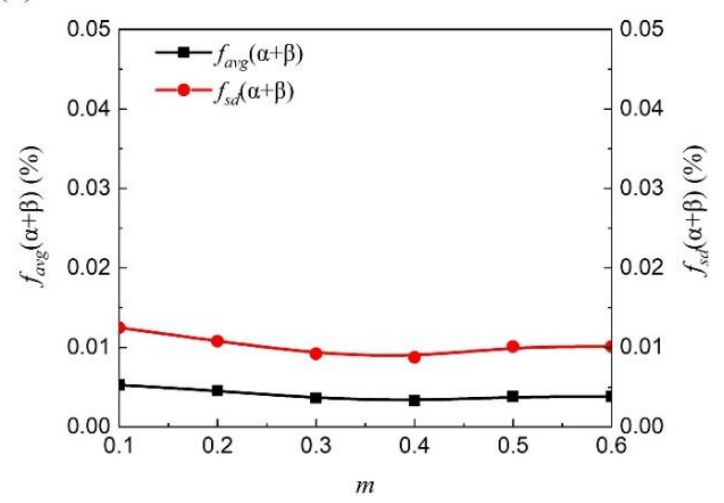

Fig. 8. Evolutions of $f_{\max }(\alpha+\beta), f_{\min }(\alpha+\beta), f_{\text {avg }}(\alpha+\beta)$ and $f_{s d}(\alpha+\beta)$ with the increment of $m$.
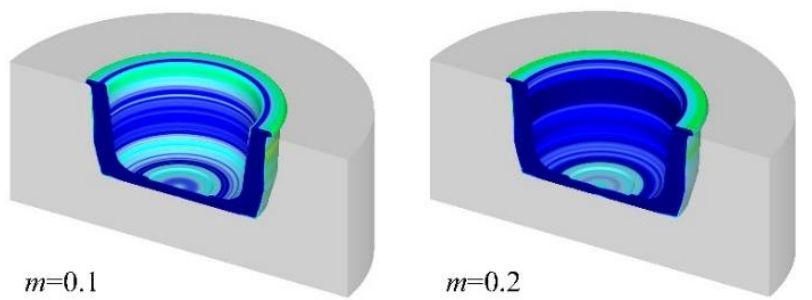

$m=0.2$
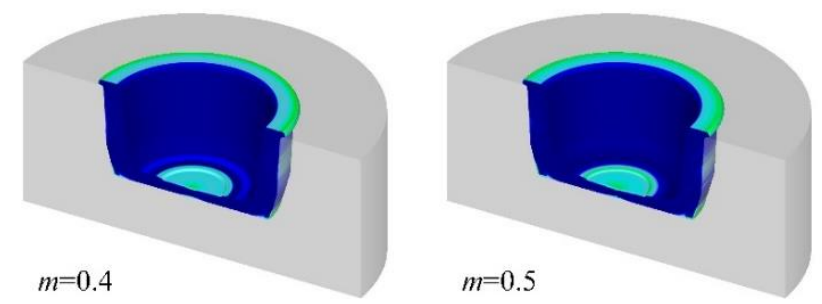

$\alpha+\beta$ phase ( $\%)$

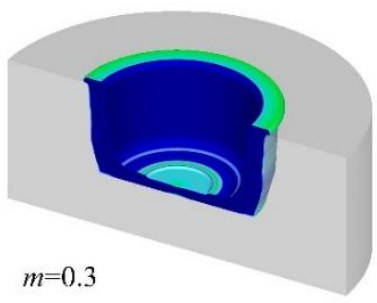

0.10

0.08

0.06

0.05

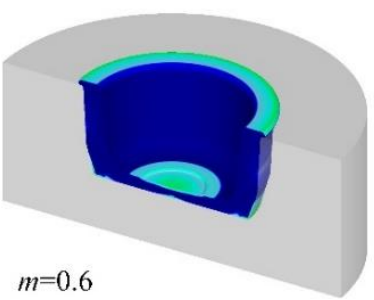

0.03

0.01

0.00

Fig. 9. Distributions of $\alpha+\beta$ phase under various friction conditions.

\section{Experimental verification}

Fig. 10(a) presents the glass lubricant-assisted hot drum forging experiments with the forging parameters described in Table 1. For Ti-6Al-4V alloy, the friction factor under glass lubricant condition 
is about 0.3 according to the work of Zhu et al. [34]. Fig. 10(b) shows the simulated result with the same forging parameters. It can be seen from Table 2 that the experimental and simulated geometries including internal and external dimensions (h, d, H and D) present good agreement with errors less than $0.53 \%$. Then, as displayed in Fig. 10(c), the microstructures at the bottom (P1) and flash (P2) areas of the forged drum are observed, which are mainly consisted of $\alpha$ and $\alpha+\beta$ phases. Finally, it can be found from Fig. 10(d) that the simulated $\alpha$ phase volume fractions qualitatively agree with the experimental ones, showing errors less than $7.6 \%$. Therefore, the 2D FE model and its simulation results are effective.
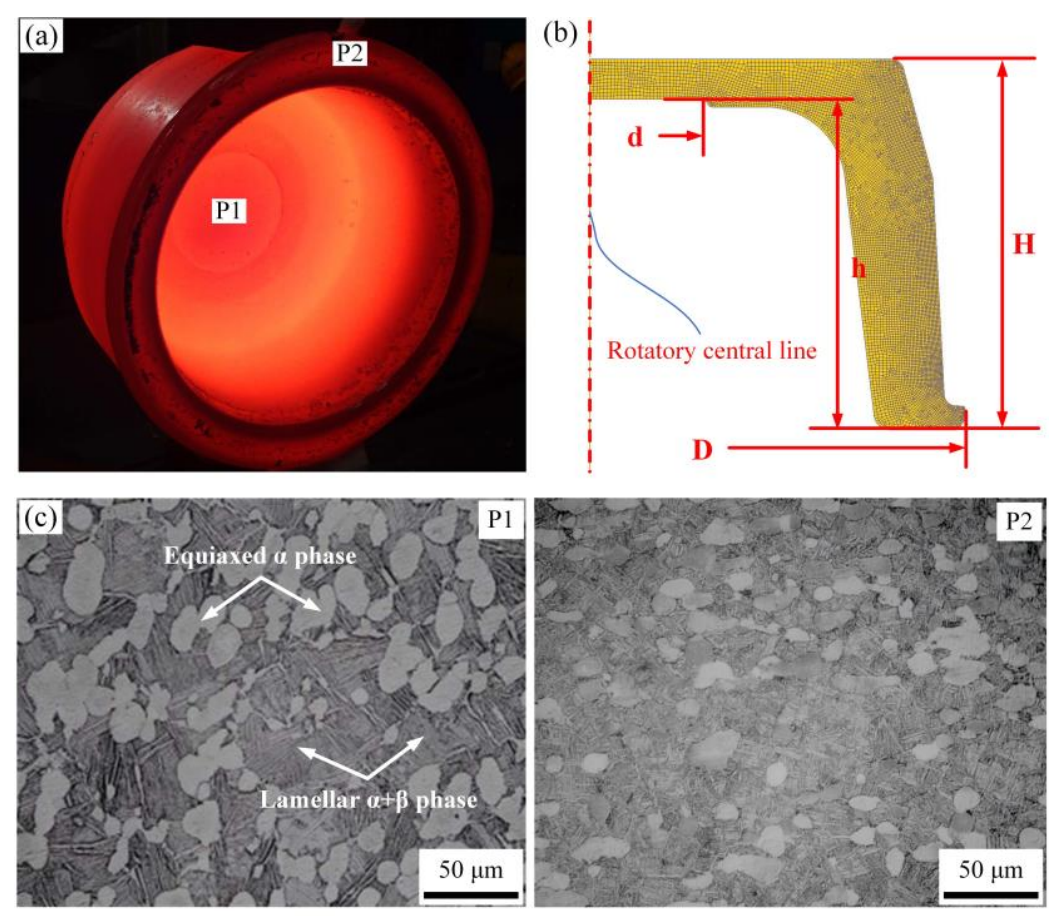

(d)

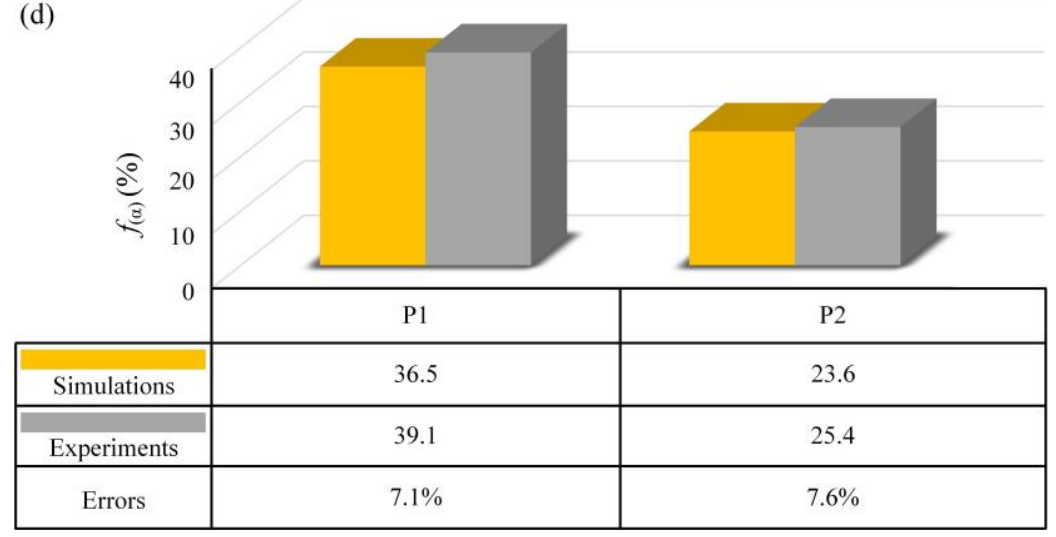

Fig. 10. Experimental (a), simulated drums (b), microstructures (c) and the $\alpha$ phase volume fractions of experimental and simulated results (d). 
Table 2 Experimental and simulated geometries.

\begin{tabular}{lcccc}
\hline \multirow{2}{*}{ Parameters } & \multicolumn{4}{c}{ Mean values (mm) } \\
\cline { 2 - 4 } & $\mathrm{h}$ & $\mathrm{d}$ & $\mathrm{H}$ & $\mathrm{D}$ \\
\hline Experimental results & 415.5 & 284.6 & 453.7 & 905.6 \\
Simulated results & 414.3 & 283.2 & 455.1 & 907.9 \\
Errors & $0.29 \%$ & $0.53 \%$ & $0.22 \%$ & $0.24 \%$ \\
\hline
\end{tabular}

\section{Conclusions}

In this paper, the influences of friction conditions on the temperature and phase transition characteristics of Ti-6Al-4V aeroengine drum in the hot forging procedure are numerically investigated and verified by experiments. The main conclusions are summarized:

(1) Unlike the decrement of $T_{\min }$, the values of $T_{\max }$ and $T_{a v g}$ increase with the increment of $m$, which is related to the heating effects of friction and deformation. Moreover, the value of $T_{s d}$ first dramatically drops, and then gradually increases as the $m$ exceeds 0.3 . This finding indicates that a reasonable range of friction is about $0.2-0.4$.

(2) Different from the invariable $f_{\max }(\alpha)$, the values of $f_{\min }(\alpha)$ and $f_{\text {avg }}(\alpha)$ decrease with the increment of $m$, which are ascribed to the $\alpha \rightarrow \beta$ phase transition prompted by the increments of $T_{\max }$ and $T_{\text {avg. }}$. Moreover, the value of $f_{(\alpha) s d}$ presents an inverse evolution, which indicates that the $\alpha$ phase distribution of the forged drum is more inhomogeneous with a poor lubricated condition.

(3) Converse to $\alpha$ phase, the values of $f_{\max }(\beta)$ and $f_{\min }(\beta)$ reveal an opposite evolution as enhancing friction, which are associated with the variations of temperature and cooling rates. Moreover, both values of $f_{\operatorname{avg}}(\beta)$ and $f_{s d}(\beta)$ increase with the increment of $m$. This finding indicates that $\beta$ phase distribution of the forged drum becomes more homogenous as improving friction conditions.

(4) Compared with $\alpha$ and $\beta$ phases, the volume fraction of $\alpha+\beta$ phase is much smaller, and the values 
of $f_{\text {max }}(\alpha+\beta), f_{\text {min }}(\alpha+\beta), f_{\text {avg }}(\alpha+\beta)$ and $f_{\text {sd }}(\alpha+\beta)$ can be regarded as constants with the increment of $m$.

These findings indicate that the $\beta \rightarrow \alpha+\beta$ phase transition hardly occurs in the drum forging operation, owing to the short phase transition time decided by high forging velocity.

Acknowledgements

The authors would like to gratefully acknowledge the financial support from the Hubei Provincial Natural Science Foundation of China (nos. 2020CFB115, 2020CFB112).

\section{Declarations}

Funding

This work is supported by the Hubei Provincial Natural Science Foundation of China (nos. 2020CFB115, 2020CFB112).

\section{Conflicts of interest}

The authors declare no competing interests.

\section{Availability of data and material}

Data are available from the corresponding author on request.

\section{Code availability}

Not applicable

\section{Ethics approval}

Not applicable

\section{Consent to participate}

Not applicable

\section{Consent for publication}

All authors consent to the publication of the manuscript in this journal. 


\section{References}

[1] Li CF, Miao BQ, Tang QS, Xi CY, Wen BC (2018) Nonlinear vibrations analysis of rotating drumdisk coupling structure. J Sound Vib 420:35-60

[2] Lin YC, Huang J, He DG, Zhang XY, Wu Q, Wang LH, Chen C, Zhou KC (2019) Phase transformation and dynamic recrystallization behaviors in a Ti55511 titanium alloy during hot compression. J Alloy Compd 795:471-482

[3] Luo SY, Zhu DH, Qian DS, Hua L, Yan SJ, Zhang JJ (2016) Effects of friction model on forging process of Ti-6Al-4V turbine blade considering the influence of sliding velocity. Int J Adv Manuf Technol 82:1993-2002

[4] Zhu DH, Feng XZ, Xu XH, Yang ZY, Li WL, Yan SJ, Ding H (2020) Robotic grinding of complex components: A step towards efficient and intelligent machining-challenges, solutions, and applications. Robot Comput Integr Manuf 65:101908

[5] Luo SY, Zhu DH, Hua L, Qian DS, Yan SJ, Yu FP (2016) Effects of process parameters on deformation and temperature uniformity of forged Ti-6Al-4V turbine blade. J Mater Eng Perform $25: 4824-4836$

[6] Luo SY, Wang Q, Zhang P, Li J, Liu QL (2020) Effect of friction conditions on phase transformation characteristics in hot forging process of Ti-6Al-4V turbine blade. J Mater Res Technol 9:2107-2115

[7] Ji RJ, Wang HY, Wang BK, Jin H, Liu YH, Cheng WH, Cai BP, Li XP (2020) Removing loose oxide layer and producing dense $\alpha$-phase layer simultaneously to improve corrosion resistance of Ti-6Al4V titanium alloy by coupling electrical pulse and ultrasonic treatment. Surf Coat Technol $384: 125329$

[8] Shao H, Cai LL, Wang KX, Li L, Zhang GJ, Zhao YQ (2018) Microstructure and high strength- 
ductility synergy of Ti-6Al-4V alloy induced by joule heat treatment. J Mater Sci 53:16609-16617

[9] Dai JH, Xia JY, Chai LJ, Murty KL, Guo N, Daymond MR (2020) Correlation of microstructural, textural characteristics and hardness of Ti-6Al-4V sheet $\beta$-cooled at different rates. J Mater Sci $55: 8346-8362$

[10] Sha W and Savko M (2009) Titanium Alloys: Modelling of Microstructure, Properties and Applications. Woodhead Publishing Limited and CRC Press

[11] Malinov S, Markovsky P, Sha W, Guo Z (2001) Resistivity study and computer modelling of the isothermal transformation kinetics of Ti-6Al-4V and Ti-6Al-2Sn-4Zr-2Mo-0.08Si alloys. J Alloy Compd 314:181-192

[12] Quan GZ, Pan J, Zhang ZH (2016) Phase transformation and recrystallization kinetics in space-time domain during isothermal compressions for Ti-6Al-4V analyzed by multi-field and multi-scale coupling FEM. Mater Des 94:523-535

[13] Bruschi S, Buffa G, Ducato A, Fratini L, Ghiotti A (2015) Phase evolution in hot forging of dual phase titanium alloys: Experiments and numerical analysis. J Manuf Process 20:382-388

[14] Luo SY, Yao JN, Zou GM, Li J, Jiang J, Yu FP (2020) Transformation characteristics of temperature and phases within Ti-6Al-4V aeroengine drum in hot forging and air cooling procedures. J Mater Res Technol 9:8235-8244

[15] Ducato A, Buffa G, Fratini L, Shivpuri R (2015) Dual phase titanium alloy hot forging process design: experiments and numerical modeling. Adv Manuf 3:269-281

[16] Buffa G, Ducato A, Fratini L (2013) FEM based prediction of phase transformations during friction stir welding of Ti6Al4V titanium alloy. Mater Sci Eng A 581:56-65

[17] Luo SY, Li J, Yu FP (2020) Numerical analysis of phase transformation characteristics in hot forging 
and subsequent air cooling processes of Ti-6Al-4V turbine blade. Int $\mathrm{J}$ Adv Manuf Technol $106: 1521-132$

[18] JMatPro Demo version, Sente Software Ltd., Surrey Technology Centre 40 Occam Road GU2 7YG United Kingdom, 2015.

[19] Luo SY, Zhu DH, Hua L, Qian DS, Yan SJ (2017) Numerical analysis of die wear characteristics in hot forging of titanium alloy turbine blade. Int J Mech Sci 123:260-270

[20] Luo SY, Yao JN, Zou GM, Li J, Jiang J, Yu FP (2020) Influence of forging velocity on temperature and phase transformation characteristics of forged Ti-6Al-4V aeroengine drum. Int J Adv Manuf Technol 110:3101-3111

[21] Luo SY, Yao JN, Li J, Du H, Liu HY, Yu FP (2020) Influence of forging velocity on temperature and phases of forged Ti-6Al-4V turbine blade. J Mater Res Technol 9:12043-12051

[22] Zafari A, Barati MR, Xia K (2019) Controlling martensitic decomposition during selective laser melting to achieve best ductility in high strength Ti-6Al-4V. Mater Sci Eng A 744:445-455

[23] Li BX, Zhang S, Zhang Q, Li LL (2019) Simulated and experimental analysis on serrated chip formation for hard milling process. J Manuf Process 44:337-348

[24] Liang XL, Liu ZQ, Wang QQ, Wang B, Ren XP (2020) Tool wear-induced microstructure evolution in localized deformation layer of machined Ti-6Al-4V. J Mater Sci 55:3636-3651

[25] Li BX, Zhang S, Zhang Q, Chen J, Zhang J (2018) Modelling of phase transformations induced by thermo-mechanical loads considering stress-strain effects in hard milling of AISI H13 steel. Int J Mech Sci 149:241-253

[26] Lu XF, Lin X, Chiumenti M, Cervera M, Hu YL, Ji XL, Ma L, Huang WD (2019) In situ measurements and thermos-mechanical simulation of Ti-6Al-4V laser solid forming processes. Int 
J Mech Sci 153-154:119-130

[27] Zhou WB, Lin JG, Dean TA, Wang LL (2018) Feasibility studies of a novel extrusion process for curved profiles: Experimentation and modelling. Int J Mach Tools Manuf 126:27-43

[28] Ren JX, Cai J, Zhou JH, Shi KN, Li XY (2018) Inverse determination of improved constitutive equation for cutting titanium alloy Ti-6Al-4V based on finite element analysis. Int J Adv Manuf Technol 97:3671-3682

[29] Bai SW, Fang G, Zhou J (2019) Integrated physical and numerical simulations of weld seam formation during extrusion of magnesium alloy. J Mater Process Technol 266:82-95

[30] Alimirzaloo V, Sadeghi MH, Biglari FR (2012) Optimization of the forging of aerofoil blade using the finite element method and fuzzy-Pareto based genetic algorithm. J Mech Sci Technol 26:18011810

[31] Dąbrowski R (2011) The kinetics of phase transfermations during continuous cooling of the Ti6Al4V alloy from the single-phase $\beta$ range. Arch Metall Mater 56:703-707

[32] Lin YC, Tang Y, Zhang XY, Chen C, Yang H, Zhou KC (2019) Effects of solution temperature and cooling rate on microstructure and micro-hardness of a hot compressed Ti-6Al-4V alloy. Vacuum 159:191-199

[33] Pan ZP, Liang SY, Garmestani H, Shih DS (2016) Prediction of machining-induced phase transformation and grain growth of Ti-6Al-4V alloy. Int J Adv Manuf Technol 87:859-866

[34] Zhu YC, Zeng WD, Ma X, Tai QG, Li ZH, Li XG (2011) Determination of the friction factor of Ti$6 \mathrm{Al}-4 \mathrm{~V}$ titanium alloy in hot forging by means of ring-compression test using FEM. Tribol Int 44:2074-2080 
(a)

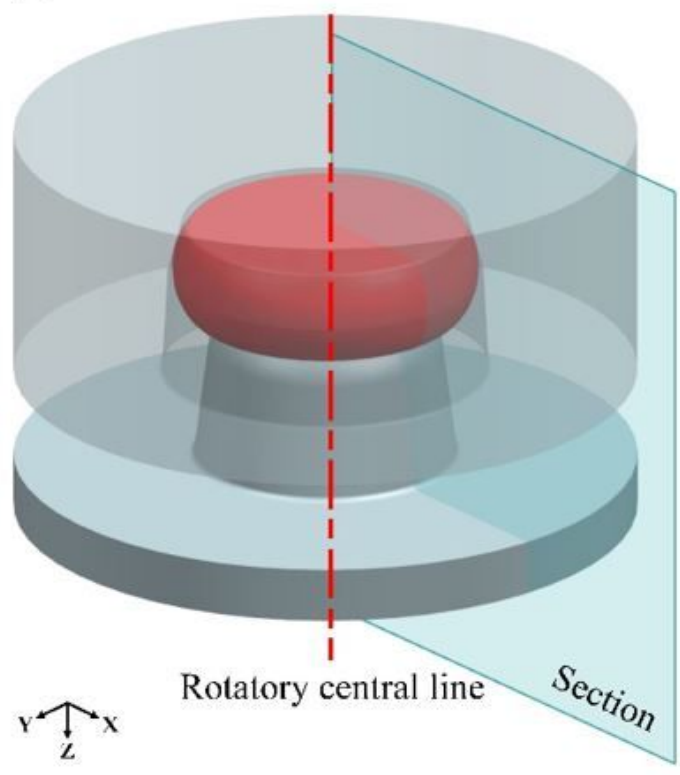

(b)

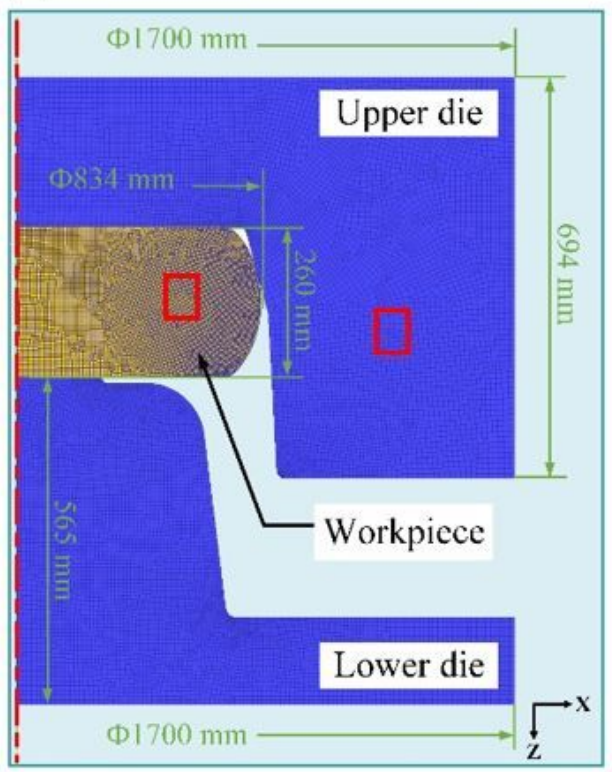

(c)

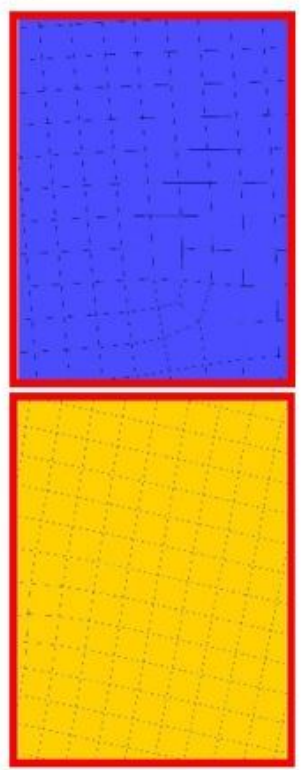

\section{Figure 1}

Drum structure (a), 2D simplified FE model (b) and the mesh details of dies and workpiece (c).

(a)

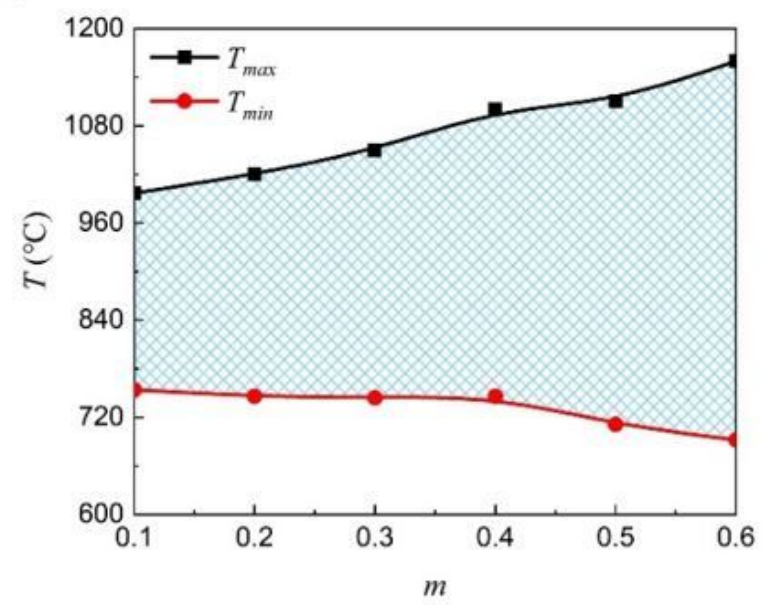

(b)

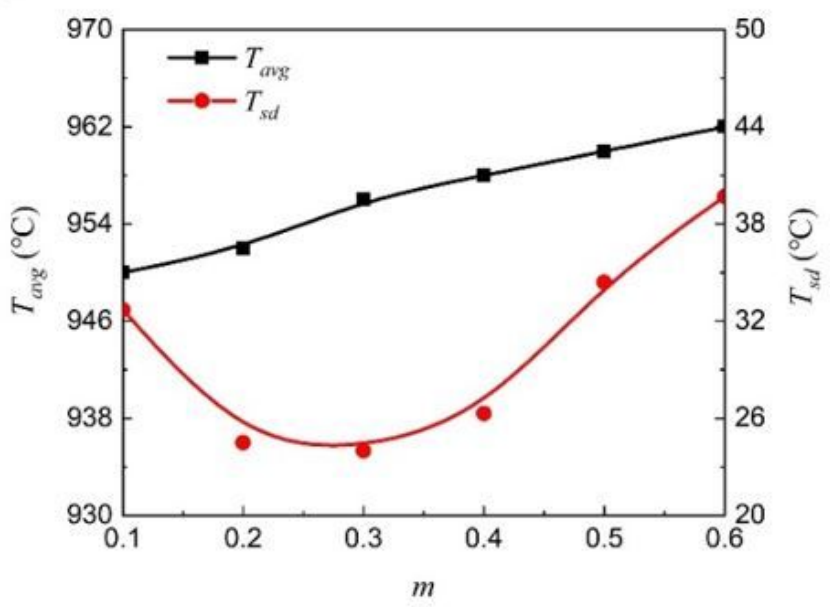

Figure 2

Evolutions of Tmax, Tmin, Tavg and Tsd with the increment of $\mathrm{m}$. 
Temperature $\left({ }^{\circ} \mathrm{C}\right)$
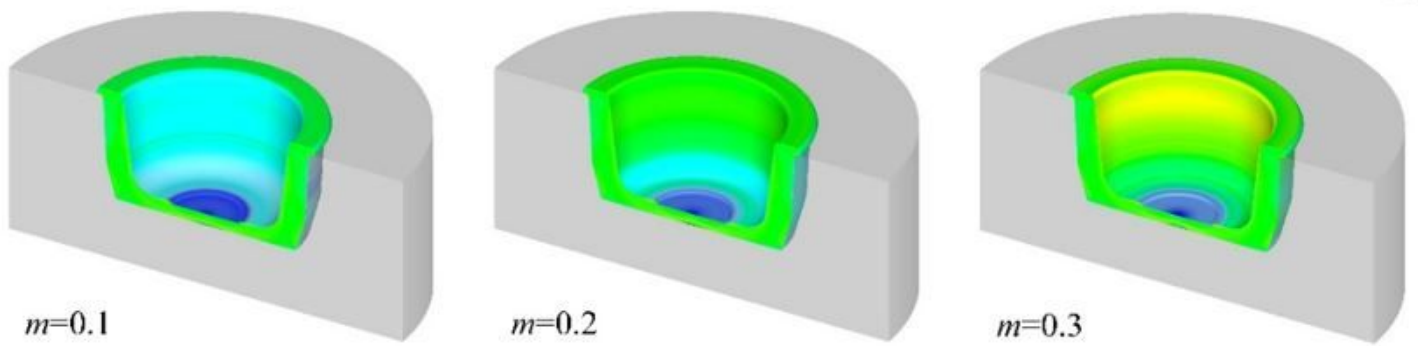

1160

1060

1000

$m=0$.

$m=0.2$

$m=0.3$
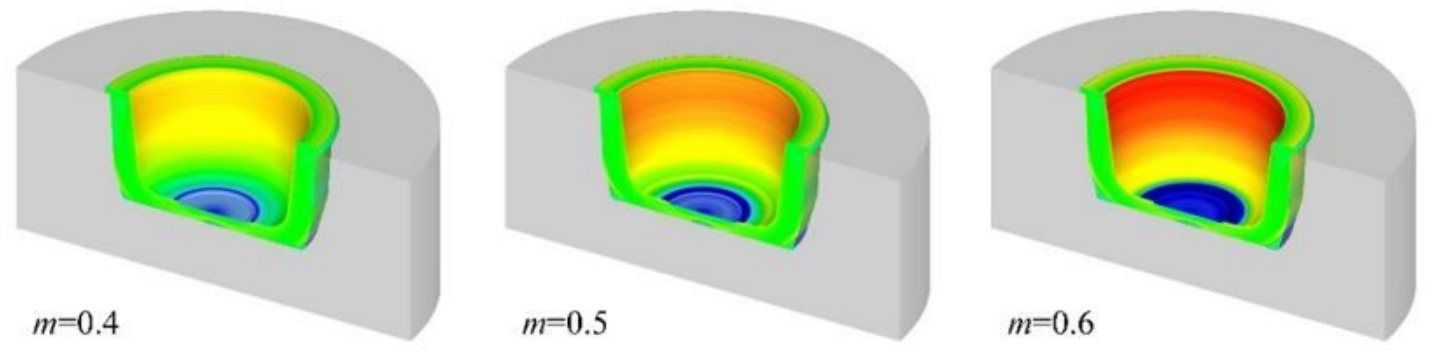

847

768

690

\section{Figure 3}

Distributions of temperature under various friction conditions.

(a)

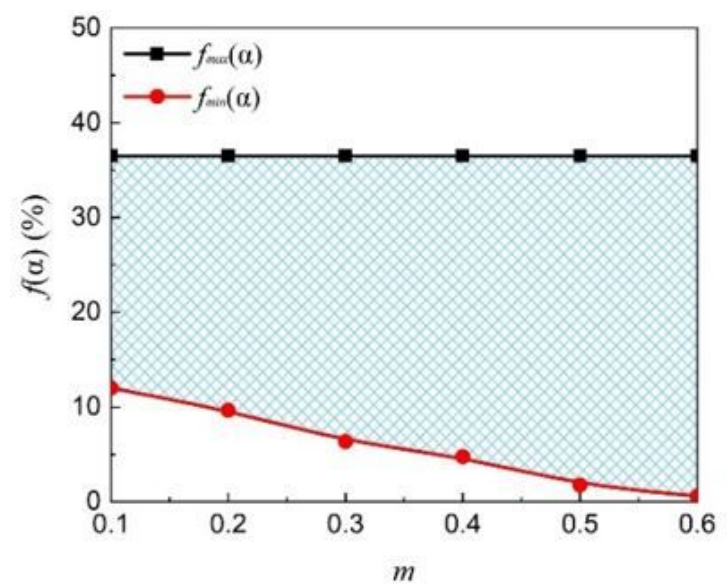

(b)

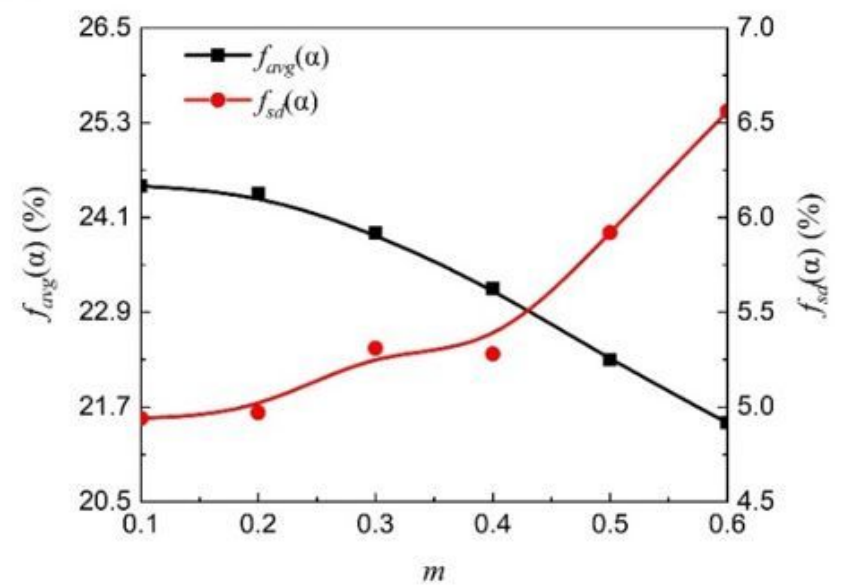

\section{Figure 4}

Evolutions of $f \max (a), f \min (a), f a v g(a)$ and $f s d(a)$ with the increment of $m$. 
$\alpha$ phase (\%)
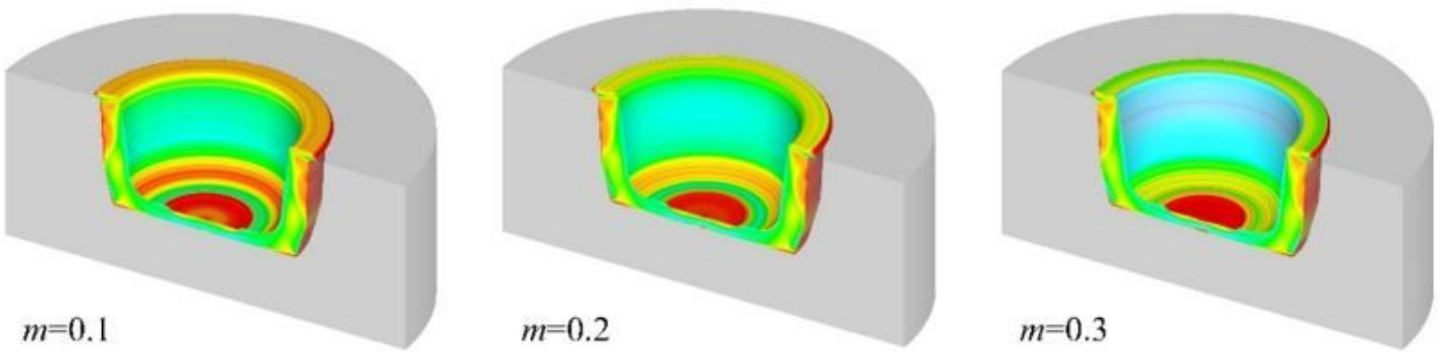

36.5

30.4

24.3

18.3
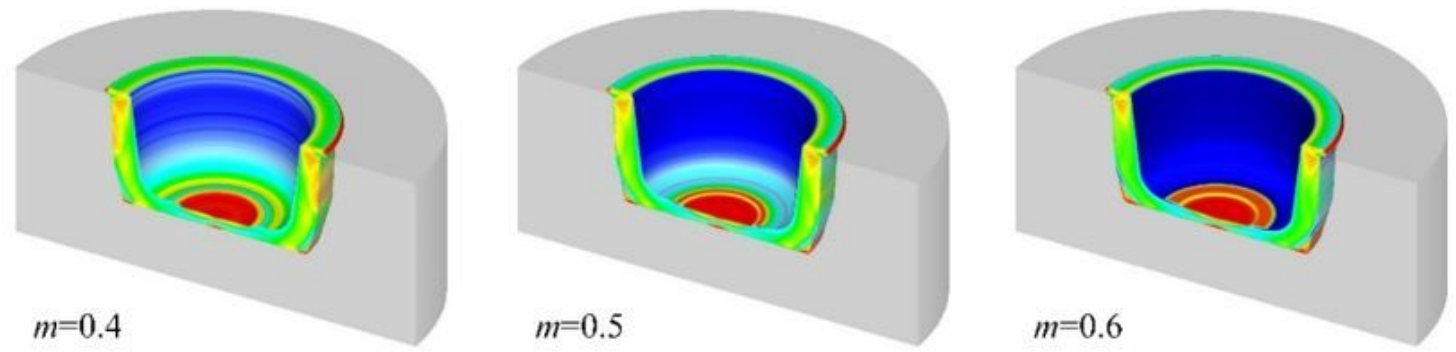

6.1

0.0

\section{Figure 5}

Distributions of a phase under various friction conditions.

(a)

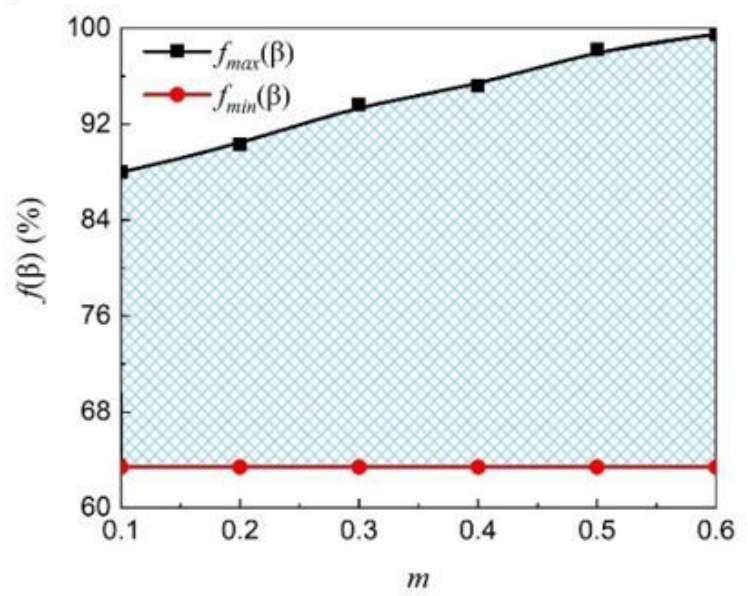

(b)

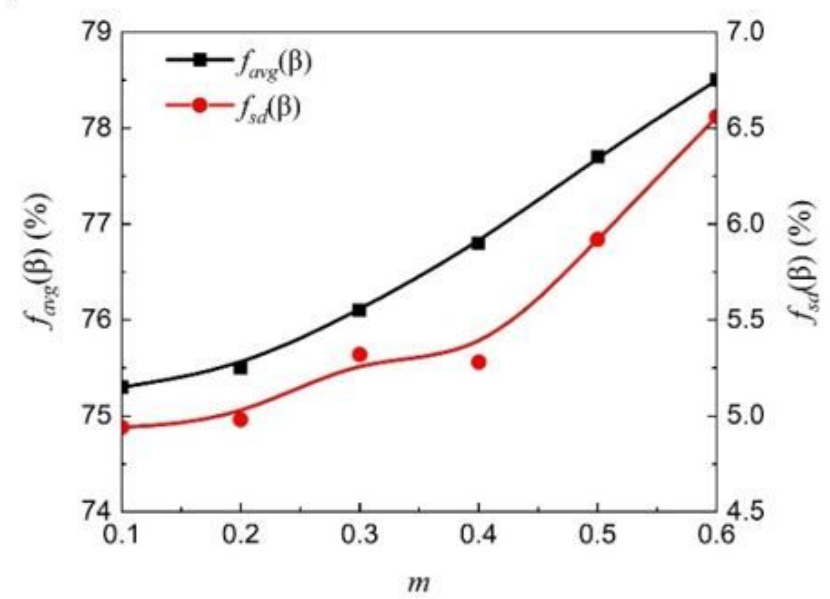

Figure 6

Evolutions of $f \max (\beta), f \min (\beta), f a v g(\beta)$ and $f s d(\beta)$ with the increment of $m$. 

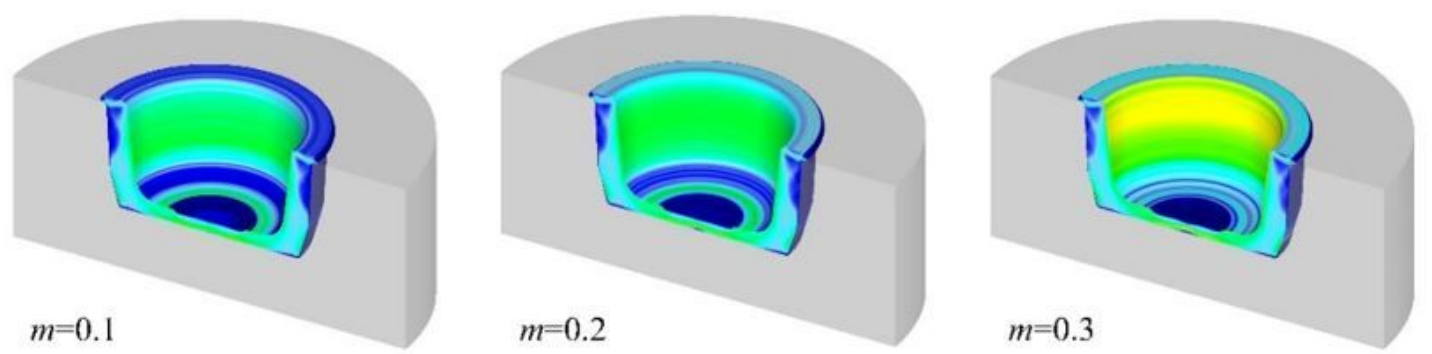

$\beta$ phase $(\%)$

$m=0$.

$m=0.2$

$m=0.3$

100.0

93.4

87.3

81.3
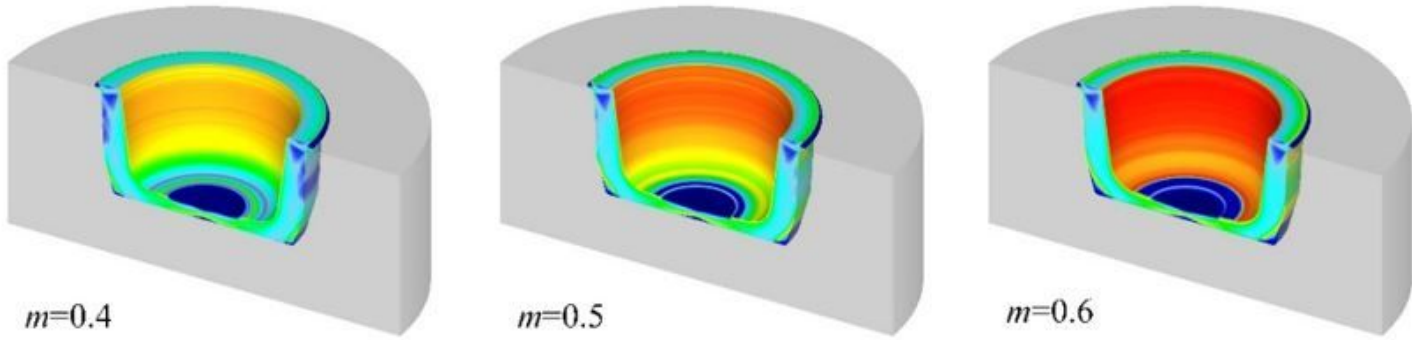

75.2

69.1

63.0

\section{Figure 7}

Distributions of $\beta$ phase under various friction conditions.

(a)

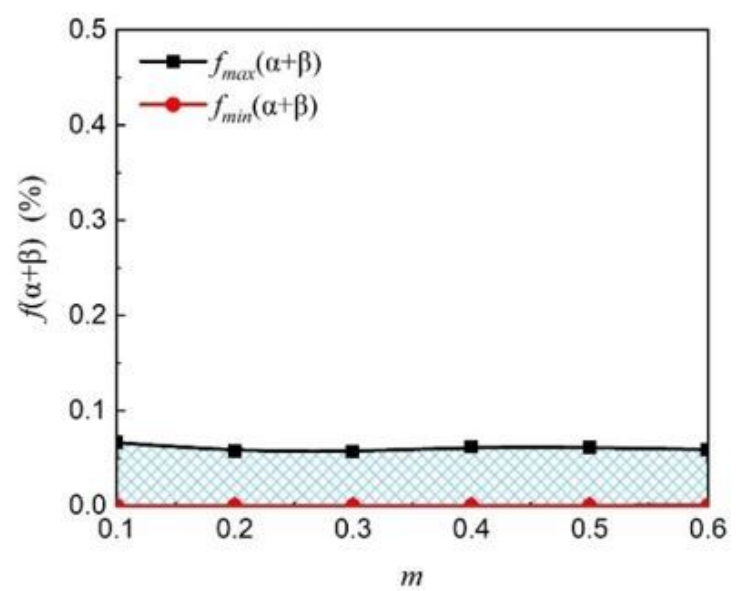

(b)

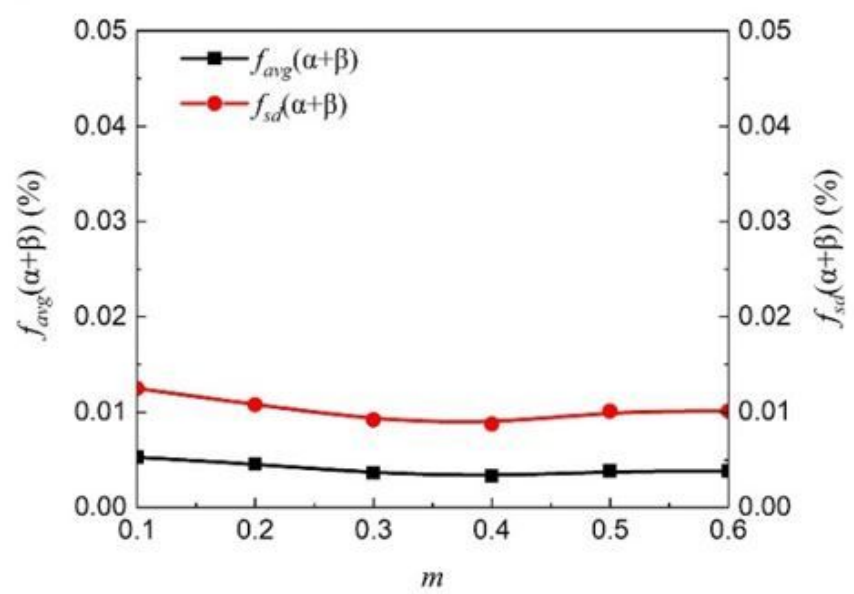

Figure 8

Evolutions of $f \max (\alpha+\beta), f \min (\alpha+\beta), f a v g(\alpha+\beta)$ and $f s d(\alpha+\beta)$ with the increment of $m$. 

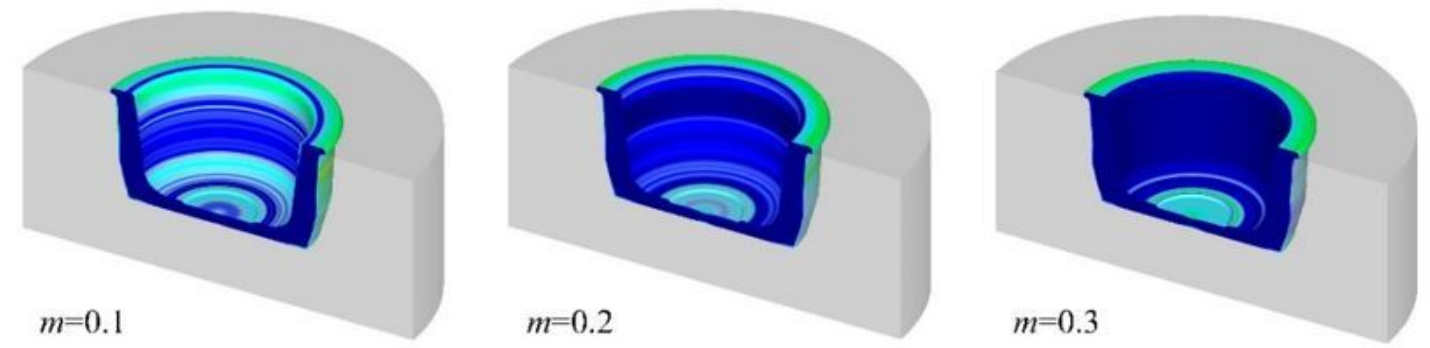

$\alpha+\beta$ phase $(\%)$

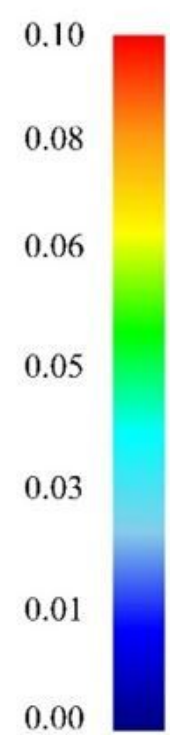

Figure 9

Distributions of $a+\beta$ phase under various friction conditions. 


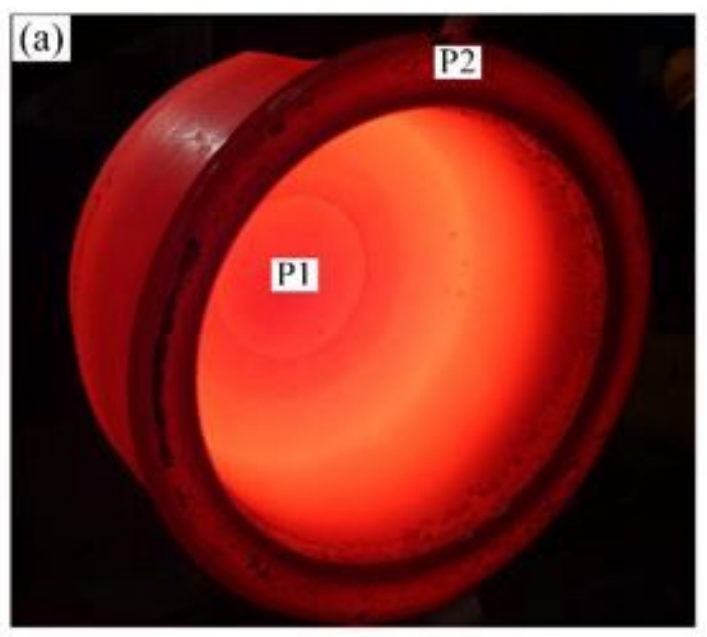

(b)
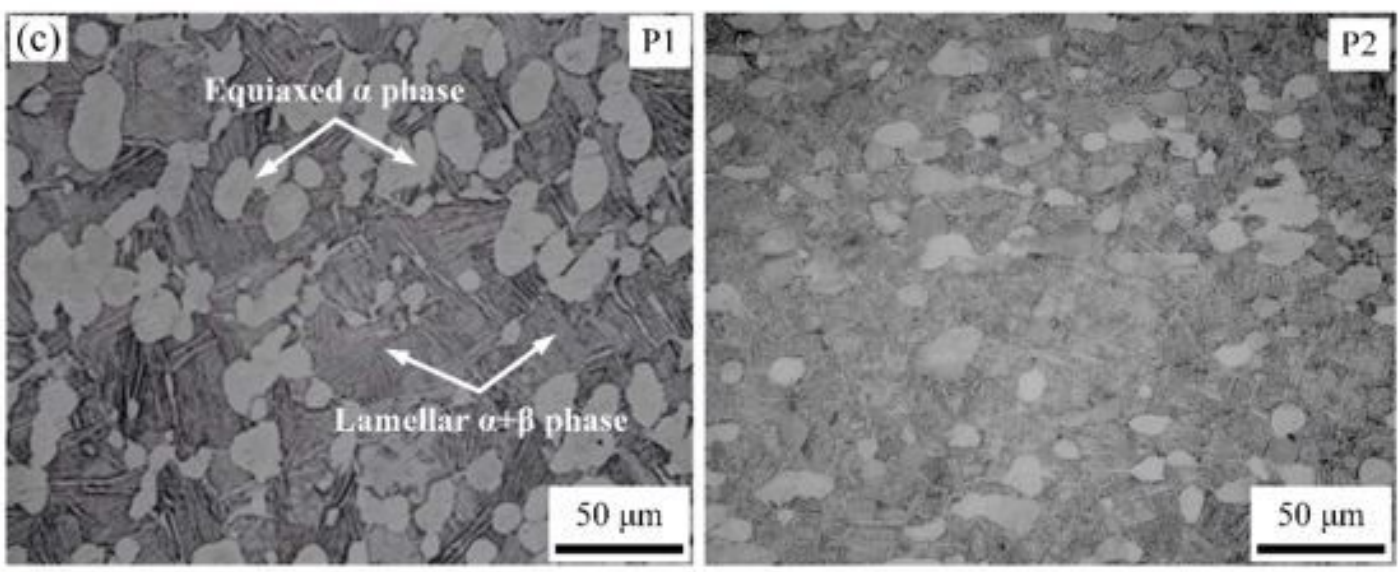

(d)

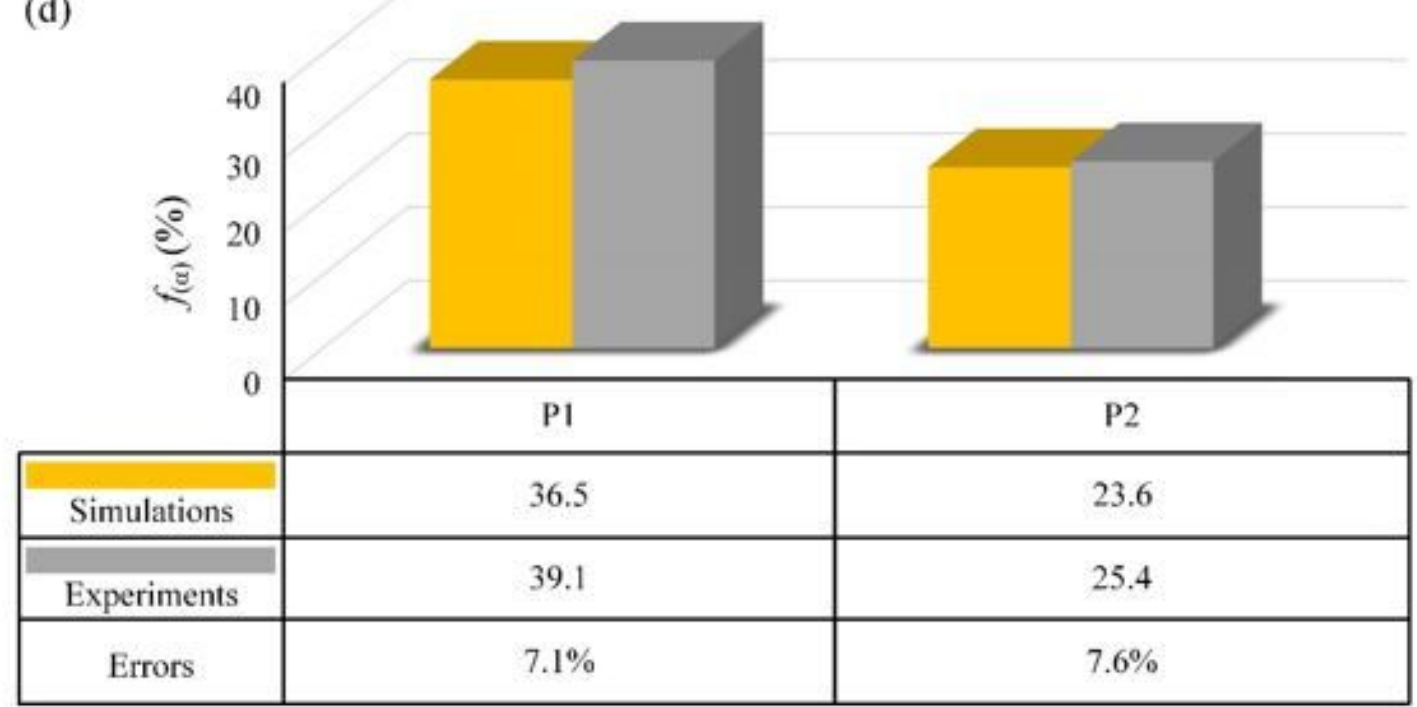

Figure 10

Experimental (a), simulated drums (b), microstructures (c) and the a phase volume fractions of experimental and simulated results (d). 